\section{In Vitro Flowering of Plantlets Regenerated from Zygotic Embryo- derived Somatic Embryos of Ginseng}

\author{
Haeng S. Lee, Jang R. Liu, Seung G. Yang, and Young H. Lee \\ Genetic Engineering Center, Korea Institute of Science and Technology, \\ P. O. Box 131, Cheongryang, Seoul, Korea
}

Kwang-W. Lee

Department of Botany, Seoul National UniversitySeoul, Korea

Additional index words. juvenility, somatic embryogenesis, plant growth regulators,

Panax ginseng

\begin{abstract}
Mature zygotic embryos dissected from ginseng (Panax ginseng C.A. Meyer) seeds were cultured on Murashige and Skoog (MS) medium containing various concentrations of 2,4-D and kinetin. Somatic embryos were induced directly from cotyledonary tissue and from intervening callus. The frequency of somatic embryo induction was up to $55 \%$ of zygotic embryo explants. Upon transfer onto half-strength MS medium supplemented with $1 \mathrm{mg} \mathrm{BA} /$ liter and $1 \mathrm{mg} \mathrm{GA} /$ /iter, most somatic embryos developed into plantlets. More than $50 \%$ of the plantlets flowered after 4 weeks of culture, and some developed immature fruits in vitro. These results indicate that adulthood of ginseng root explants is not a prerequisite for flowering of plantlets regenerated through somatic embryogenesis. Chemical names used: (2,4 -dichlorophenoxy) acetic acid (2,4-D); N-(2-furanylmethyl) -1H-purin-6-amine(kinetin); N-(phenylmethyl) -1H-purin-6amine (BA); gibberellic acid $\left(\mathbf{G A}_{3}\right)$.
\end{abstract}

A somatic cell may develop into a mature embryo morphologically similar to a zygote in the ovule. Somatic embryogenesis, first reported in tissue cultures of carrot (Reinert, 1958; Steward et al., 1958), has been demonstrated in a vast number of species (Ammirato, 1983). Butenko et al. (1968) first induced somatic embryos from ginseng root callus, but plant regeneration was not achieved. Callus and organized structures were induced from ginseng cotyledon explants cultured on medium without plant growth regulators (PGRs) (Harn and Lee, 1974) and subsequently were grown to plantlets. The leaf-like structures were later thought to be somatic embryos (C. Harn, personal communication). Chang and Hsing- (1980a) induced somatic embryos from root callus derived from 6-year-old plants. When subculture on medium containing BA and $\mathrm{GA}_{3}$, the somatic embryos grew into plantlets and subsequently flowered (Chang and Hsing, 1980b). Ginseng undergoes a 3-year juvenile period before flowering under field conditions. Therefore, Chang and Hsing's work had demonstrated drastic shortening of the juvenile period by in vitro manipulation (Bernier et al., 1981; Scorza, 1982; Zimmerman et al., 1985). Since flowering of

Received for publication 8 Jan. 1990. This research was supported by a grant (N118(5)-25455) from the Ministry of Science and Technology of Korea to J.R. L. We thank Daniel J. Cantliffe, Raymond P. Chee, Chu B. Hong, and Hyouk Joung for their critical reading of this manuscript The cost of publishing this paper was defrayed in part by the payment of page charges. Under postal regulations, this paper therefore must be hereby marked advertisement solely to indicate this fact. explants from juvenile plants is rare (Scorza, 1982), the question remains if the adulthood of 6-year-old root explants contributed to the flowering of the ginseng plantlets regenerated through somatic embryogenesis. We conducted experiments to determine if somatic embryos derived from juvenile explants of ginseng, such as zygotic embryo tissues, were capable of flowering.

Dehusked seeds of ginseng that had been

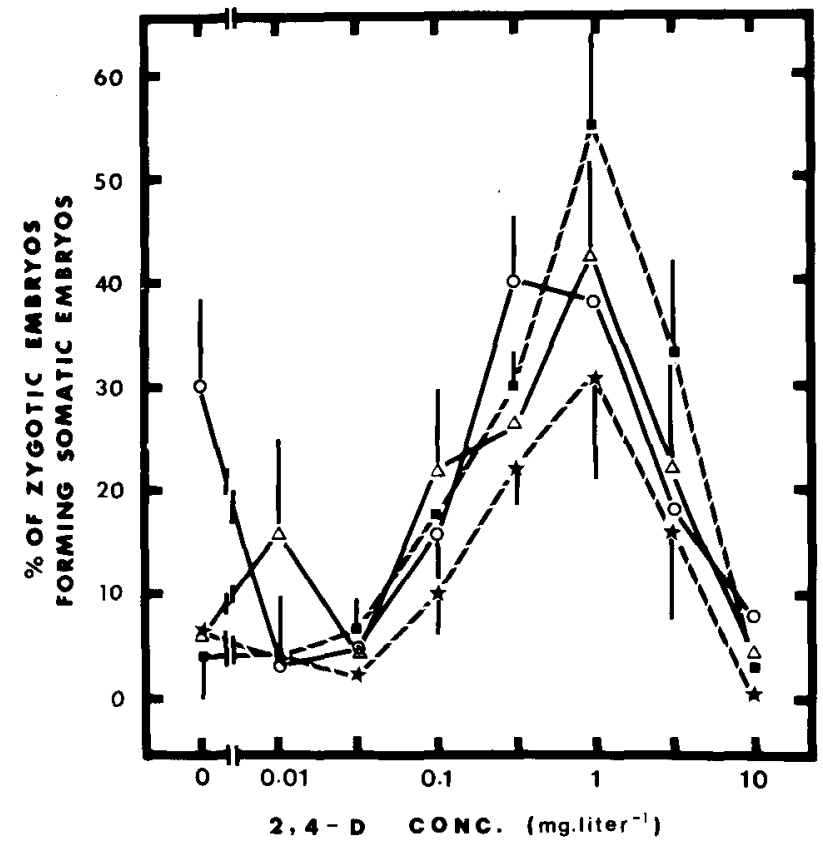

Fig. 1. Effects of 2,4-D and kinetin concentrations in the culture medium on the formation of somatic embryos from zygotic embryos. Concentrations of the kinetin (mg liter $\left.{ }^{-1}\right): 0(\mathrm{O}-\mathrm{O}), 0.01$ (D- $), 0.1(\triangle-\triangle)$, and $1(\star-\star)$. Data were collected after 10 weeks of culture. Vertical bars represent \pm SD. stored at $4 \mathrm{C}$ in darkness were disinfested with $70 \%$ ethanol for 5 min and, subsequently, in $50 \%$ Clorox solution for 20 min. Seeds were rinsed three times with sterile double-distilled water before zygotic embryos were dissected out and placed onto medium. The basal culture medium for zygotic embryo culture consisted of Murashige and Skoog (1962) inorganic salts, $100 \mathrm{mg}$ myo-inositol/ liter, $0.4 \mathrm{mg}$ thiamine. HC1/liter, $30 \mathrm{~g}$ sucrose/liter, and $8 \mathrm{~g}$ Bacto agar/liter (MS medium). The medium was supplemented with factorial combinations of either $0,0.01,0.03$, $0.1,0.3,1,3$, or $10 \mathrm{mg} \mathrm{2,4-D/liter}$ and either $\mathrm{O}, 0.01,0.1$ or $1 \mathrm{mg}$ kinetin/liter. The agar was washed three times with double-distilled water before being added to medium. All media were adjusted to $\mathrm{pH} 5.8$ before autoclaving $200-\mathrm{ml}$ aliquots for $15 \mathrm{~min}$ at $121 \mathrm{C}$. Twenty-five $\mathrm{ml}$ of medium was dispensed into $87 \times 15-\mathrm{mm}$ plastic petri dishes. Five embryos were placed in each petri dish and sealed with parafilm. Ten replications were prepared for each treatment. Incubation was at $25 \mathrm{C}$ in darkness for 10 weeks. Periodically, cultures were observed under a dissecting microscope. For the histological observation, heart-shaped somatic embryos were fixed in formalin-acetic acid-alcohol, dehydrated in a tertiary-butanol series, and embedded in paraplast. Serial sections were cut at $8 \mu \mathrm{m}$ and stained with Delafield's Hematoxylin (Chamberlain, 1924),

Callus arose from the peripheral region of zygotic embryo cotyledons on all media containing 2,4-D and kinetin after 4 weeks of culture. After 6 weeks, callus from the entire surface of the zygotic embryos, including cotyledons, hypocotyls, and radicles, gave rise to somatic embryos. The maximum frequency $(55 \%)$ of somatic embryo induction from zygotic embryos was on medium con- 

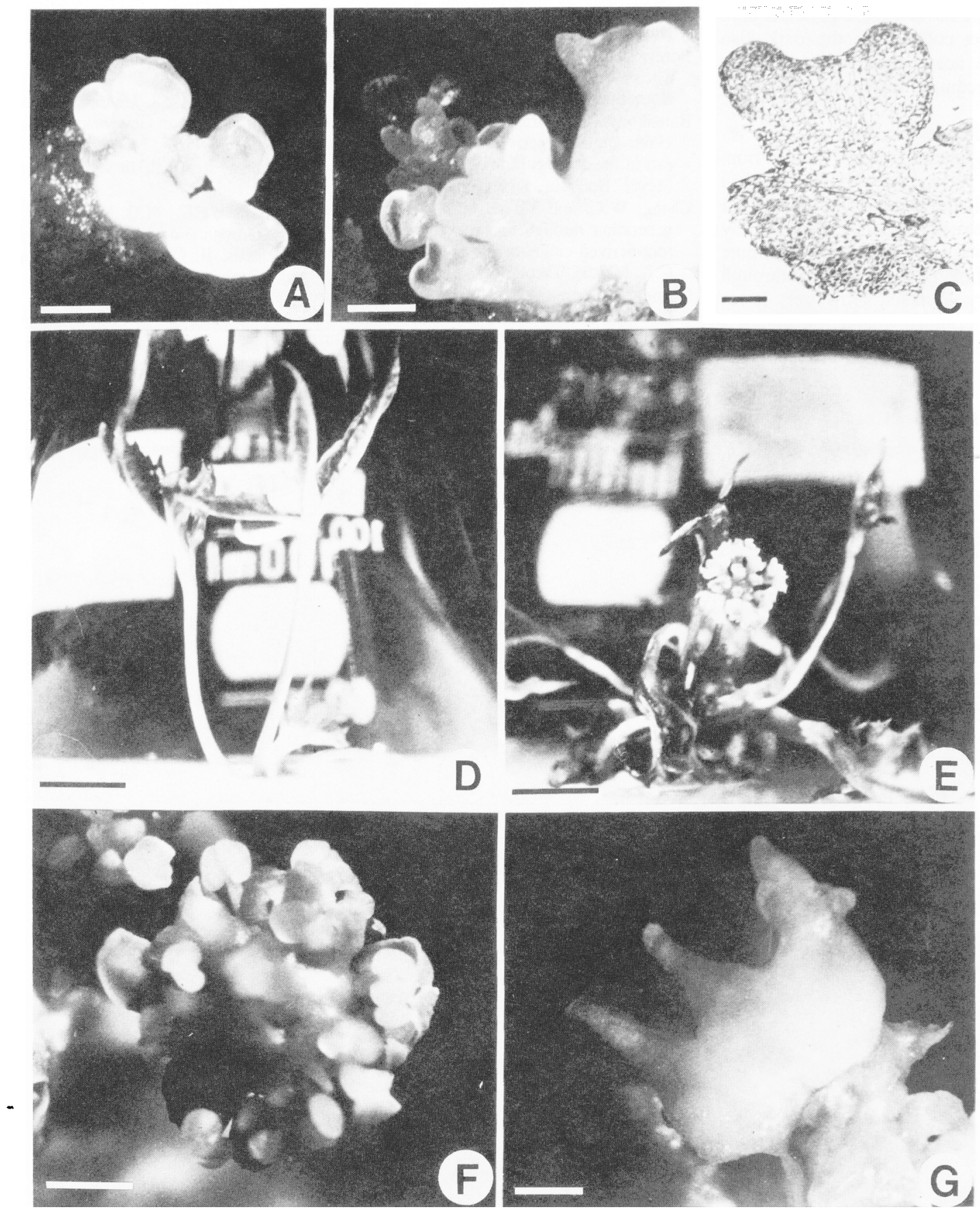

Fig. 2. Plant regeneration through somatic embryogenesis from mature zygotic embryos of ginseng and flowering of plantlets. (A) Globular to torpedoshaped somatic embryos derived from cotyledonary tissue of zygotic embryos (scale bar $=1 \mathrm{~mm}$ ). (B) Multi-cotyledonary somatic embryos (scale bar $=1 \mathrm{~mm})$. (C) Longitudinal section of a heart-shaped somatic embryo showing a bipolar organization with an integrated shoot-root axis $(\mathrm{scale}$ bar $=$ $100 \mu \mathrm{m})$. (D) A plantlet regenerated from a somatic embryo $($ scale bar $=1 \mathrm{~cm})$. (E) A flowering plantlet (scale bar $=1 \mathrm{~cm})$. (F) Flowers with welldeveloped anthers $($ scale bar $=500 \mu \mathrm{m})$. $(\mathbf{G})$ An immature fruit borne by a plantlet $($ scale bar $=1 \mathrm{~mm})$.

taining $1 \mathrm{mg}$ 2,4-D/liter and $0.01 \mathrm{mg}$ kinetin/ liter. When the concentrations of 2,4-D and kinetin were $>1 \mathrm{mg} / \mathrm{liter}$ and $0.01 \mathrm{mg} / \mathrm{liter}$, respectively, the-frequency declined (Fig. 1). Somatic embryos were also produced from $30 \%$ of the cotyledons of zygotic embryos on medium without PGRs. They were induced either directly from explants or from intervening callus, which was in accord with the description by Ham and Lee (1974). Usually, somatic embryos of various developmental stages coexisted on an individual explant (Fig. 2A). Many of the somatic em- bryos had more than two cotyledons (Fig. 2B). Histological examination of the heartshaped embryos revealed a bipolar organization with an integrated shoot-root axis (Fig. 2C).

Cotyledonary somatic embryos grew into plantlets when transferred onto half-strength MS medium supplemented with $1 \mathrm{mg} \mathrm{BA} /$ liter and $1 \mathrm{mg} \mathrm{GA} /$ iter in a 125 -ml Erlenmeyer flask at 16-hr photoperiod with 19 $\mu \mathrm{E} \cdot \mathrm{s}^{-1} \cdot \mathrm{m}^{-2}$ produced by cool-white fluorescent tubes (Chang and Hsing, 1980b). Most plantlets produced more than two epicotyls
(Fig. 2D). Subsequently, more than $50 \%$ of the plantlets flowered after 4 weeks of culture in vitro (Fig. 2E). Three to 15 flower buds developed from an umbel. Flower diameter was $\approx 2 \mathrm{~mm}$, which was much smaller than flowers from ginseng plants grown under field conditions. Each flower had five pale-yellow petals and well-developed anthers (Fig. 2F). About 3 weeks later, a few ovaries developed into immature fruits while cultured in vitro (Fig. 2G). Using a staining method, Chang and Hsing (1980b) demonstrated that $90 \%$ of the pollen grains obtained 
from in vitro flowers of ginseng were viable, but they did not show if these plantlets bore fruits. Plantlets cultured in the dark also flowered (data not shown), indicating that light was not required for in vitro flowering of ginseng.

This study demonstrated that plantlets regenerated from somatic embryos derived from, juvenile tissue were capable of flowering in vitro. This indicates that the maturity of root explants in the experiment conducted by Chang and Hsing (1980b) did not contribute to flowering of plantlets regenerated through somatic embryogenesis. However, it remains to be determined whether the plantlets flowered on media containing BA and GA, will continue to flower on media without PGRs.

\section{Literature Cited}

Ammirato, P.V. 1983. Embryogenesis, p. 82-123. [n: D.A. Evans, W.R. Sharp, P.V. Ammirato, and Y. Yamada (eds.). Handbook of plant cell culture. vol. 1. Macmillan, New York.

Bernier, G., J.M. Kinet, and R.M. Sachs. 1981. The physiology of flowering. vol. 1. CRC Press, Boca Raton, Fla. p. 118.

Butenko, R., I.V. Brushwitzky, and L.I. Slepyan. 1968. Organogenesis and somatic embryogenesis in the tissue culture of Panax ginseng C.A. Meyer. Bet. Zh., Kyyiv 7:906-911.

Chang, W.C. and Y.I. Hsing. 1980a. Plant regeneration through somatic embryogenesis in root-derived callus of ginseng (Panax ginseng C.A. Meyer). Theor. Appl. Genet. 57:133-135.

Chang, W.C. and Y.I. Hsing. 1980b. In vitro flowering of embryoids derived from mature root callus of ginseng (Panax ginseng). Nature 284:341-342.

Chamberlain, C.J. 1924. Methods in plant histology. University of Chicago Press, Chicago.

Ham, C. and Y.I. Lee. 1974. Studies on the. cotyledon culture of Panur ginseng. Korean J. Bet.
17:171-174.

Murashige, T. and F. Skoog. 1962. A revised medium for rapid growth and bioassays with tobacco tissue cultures. Physiol. Plant. 15:473497.

Reinert, J. 1958. Untersuchungen über die Morphogenese an Gewebekulturen. Ber. Deut. Bet. Ges. 71:15.

Scorza, R. 1982. In vitro flowering. Hort. Rev. 4:106-127.

Steward, F. C., M.O. Mapes, and K. Mears. 1958. Growth and organized development of cultured cells. 11. Organization in cultures grown from freely suspended cells. Amer. J. Bet. 45:705708.

Zimmerman, R. H., W.P. Hackett, and R.P. Pharis. 1985. Hormonal aspects of phase change and precocious flowering, p. 79-115. In: R.P. Pharis and D.M. Reid (eds.). Encyclopedia of plant physiology. New series. vol. 11. Hormonal regulation of development. 111: Role of environmental factors. Springer-Verlag Berlin. 